\title{
Migraine and Stroke: What's the Link? What to Do?
}

\author{
Anna Gryglas $^{1,2} \cdot$ Robert Smigiel $^{2}$
}

Published online: 10 March 2017

(C) The Author(s) 2017. This article is published with open access at Springerlink.com

\begin{abstract}
Migraine and stroke are common, disabling neurologic disorders, with a high socioeconomic burden. A link between them has been proposed years ago, and various theories have been proposed to explain this bidirectional relation. However, the precise causes remain unclear. We briefly summarize existing hypotheses of this correlation seeking for recommendations for stroke prevention in migraineurs, if any exist. Among the strongest suggested theories of migrainestroke association are cortical spreading depression, endovascular dysfunction, vasoconstriction, neurogenic inflammation, hypercoagulability, increased prevalence of vascular risk factors, shared genetic defects, cervical artery dissection, and patent foramen ovale. There is no evidence that any preventive therapy in migraineurs should be used to decrease stroke risk, even in most predisposed subset of patients. However, a woman with migraine with aura should be encouraged to cease smoking and avoid taking oral contraceptives with high estrogen doses. We need further investigation to better understand the complexity of migraine-stroke association and to make firm recommendations for the future.
\end{abstract}

Keywords Migraine $\cdot$ Migraine with aura Ischemic stroke . White matter lesions $\cdot$ Migrainous infarct $\cdot$ Migraine-related stroke

This article is part of the Topical Collection on Headache

Anna Gryglas

anna.gryglas@gmail.com

1 Department of Neurology, Gromkovski Voivodship Hospital, Wroclaw, Poland

2 Department of Pediatric Propedeutics and Rare Diseases, Wroclaw Medical University, Wroclaw, Poland

\section{Introduction}

A complex association between migraine and stroke has been discussed for over 40 years [1]. These 2 diseases, one seemingly benign and the second often severe and catastrophic, remain common neurologic disorders with a high socioeconomic burden [2•]. Stroke is the second most common cause of death worldwide and the third most common cause of disability $[3,4]$. The prevalence of all strokes in adults has been estimated at $2.9 \%$ with unclear predominance among men [5, 6]. Migraine affects about $13 \%$ of the population and the prevalence of the disease is highest in women in reproductive ages $[7,8]$. Numerous epidemiologic studies report that an overall number of stroke patients, stroke related death and global burden of stroke have an increasing tendency [2•]. It is also observed in a population of migraineurs [9]. Emerging evidence indicates that migraine is associated with white matter lesions, cardiac events and vascular diseases as well [10-12]. Among cardiovascular diseases occurring more frequently in migraineurs are hypertension, Reynaud's syndrome, ischemic heart disease and myocardial infarction, comorbidities which often accompany stroke [13-15]. A recent large prospective cohort study revealed that migraine increases the risk of myocardial infarction (hazard ratio [HR] 1.39), stroke (HR 1.62), angina/coronary revascularization procedures (HR 1.73), and cardiovascular mortality (HR 1.37) [13]. There is some evidence supporting the clinical association between migraine and hemorrhagic stroke and between migraine and transient ischemic attacks [16, 17], but a discrepancy in the literature over the strength and significance of this relationship still remains, as other studies show no association [18]. Undoubtedly the association between migraine and ischemic stroke is the strongest. The percentage of cryptogenic ischemic stroke in migraineurs tends to be higher than in controls. 


\section{Migraine-Related Stroke, Migraine Infarction, and White Matter Hyperintensities}

Up to a third of migraineurs experience transient neurologic symptoms called aura, before or during headache [19]. The risk of stroke is twice as high in migraine with aura patients, both between (migraine related stroke) and during attacks (migraine infarction) [20-22]. On the other hand, most studies revealed that migraine without aura does not increase the risk of stroke $[11,23]$. Undoubtedly there is a correlation between the frequency of migraine attacks and the risk of stroke [11, 24]. Stroke Prevention in Young Women study revealed a higher stroke risk among women having more than 12 attacks per year [25]. It has also been demonstrated that the stroke risk among migraineurs is elevated in women, among smokers, in women taking oral contraceptive pills, with recent onset of migraine, and in patients younger than 45 [11]. Interestingly, in a population aged $65+$ non-migrainous headache, rather than migraine, may be the risk factor for stroke [26]. Migraine infarction is a complication of an attack of migraine with aura. It is an uncommon condition. It occurs with the prevalence 1.4$3.4 / 100000$, which is $0.2 \%-0.5 \%$ of all ischemic strokes $[27,28]$. According to the International Classification of Headache Disorders (ICHD)-3, migrainous infarction is defined as an attack of migraine with aura in which one or more aura symptoms last more than 60 minutes and neuroimaging demonstrates an ischemic brain lesion in the relevant territory. It mostly affects young women with a history of migraine with aura [29]. Studies show 65\%$82 \%$ of migraine infarction cases are located in the posterior circulation, mostly in the cerebellum [27-31]. There are data revealing that the cerebellum is more vulnerable in migraineurs, particularly with aura, and in familial hemiplegic migraine [32]. Acute ischemic lesions are usually multiple, round- or oval-shaped, with a mean diameter of $7 \mathrm{~mm}$, and located in different arterial areas [27, 28, 31]. Magnetic resonance imaging of migraine brain, particularly T2 -weighted and FLAIR sequences, often reveal small, usually multiple hyperintensities, typically located periventricularly or in the deep white matter, which are called white matter lesions (WML) [33, 34]. WML are not specific to migraine; however, their prevalence ranges from $4 \%$ to $59 \%$ of migraine population, which is significantly higher than in controls [35]. The exact etiology and clinical significance of these abnormalities remains uncertain. Some data show that the intensification of these abnormalities increases with migraine frequency (in those with $\geq 1 \mathrm{attack} / \mathrm{month} \mathrm{OR}=2.6 ; 95 \%$ CI $1.2-6.0)(26$ Kruit 2010). A study evaluating if cognitive decline could be related to WML failed to find any association; however, there are reports indicating an enhanced risk of stroke with increase in WML volume [36]. Further investigation is needed, considering that fact that we can speculate that brain structural changes in migraine could serve as disease biomarkers and help to evaluate the risk of stroke in the future.

\section{The Underlying Mechanisms of Coincidence Migraine and Stroke}

The pathogenic mechanisms explaining the migraine-stroke association remain poorly understood, but a few hypotheses exist. Among suggested theories of migraine-stroke relation are cortical spreading depression, vasoconstriction, endovascular dysfunction, increased prevalence of vascular risk factors, shared genetic defects, cervical artery dissection, cardiac abnormalities including patent foramen ovale (PFO), neurogenic inflammation, and hypercoagulability $[11,19$, $37-43]$.

\section{Cortical Spreading Depression}

Cortical spreading depression (CSD) is the electrophysiological mechanism that underlies migraine aura [44]. Also, it plays a role in the pathogenesis of ischemic stroke, intracranial hemorrhage, subarachnoid hemorrhage, traumatic brain injury, transient global amnesia, and some other diseases [45-47]. CSD is a potent, self- propagating, short-lasting depolarization wave that moves across the cortex at a rate of $3-5 \mathrm{~mm} / \mathrm{min}$ [48]. By activation of metalloproteinases, CSD changes the permeability of the blood-brain barrier [49]. Therefore, it is associated with significant ionic and water changes and large transient increase in energy metabolism [50]. Higher oxygen and glucose expenditure accompanying CSD raises cerebral blood flow [47, 51]. Cerebral hyperemia is followed by prolonged cerebral oligaemia attributable to decreased vascular responsiveness [52]. Therefore, it may favor ischemic events in the brain [53]. In addition, in vulnerable tissue, severe hypoperfusion may follow CSD, consequently leading to enlargement of ischemic lesion [54]. Mice with human migraine mutations represent an increased vulnerability to CSD and cerebral ischemia $[37,53]$. It may be speculated that CSD could be the mechanism causing the ischemic lesion in the vulnerable brain.

\section{The Role of Endothelium}

The role of endothelium in migraine pathogenesis and migraine-associated stroke has been raised during the past decades [55]. Endothelium participates in homeostasis influencing a vascular reactivity, but also thrombolysis, thrombosis, proliferation, and apoptosis [56]. Microparticles released from endothelial cells lead to endothelial activation 
and dysfunction [57]. Among endothelial biomarkers of injured endothelium are vascular endothelial growth factor, $\mathrm{t}$ PA, von Willebrand factor, C-reactive protein, reduced nitrate levels, all of which were found in migraineurs, some only in migraineurs with aura [58, 59]. Inflammatory cytokines released in the aura phase activate the endothelium leading to procoagulatory and prothrombotic state [55]. However, research of cerebrovascular reactivity in migraineurs has demonstrated conflicting data (decreased or increased cerebral vascular reactivity) in regard to the causal relationship of endothelium dysfunction in stroke pathogenesis [60-62].

\section{Cardiovascular RF}

Migraineurs are at the heightened risk of various types of vascular events including stroke [63]. For this reason, stroke risk factors in migraineurs have been widely evaluated in the literature. Regarding hypertension, which may impair cerebral blood flow and cause alterations in cerebral artery structure, we find studies indicating the incidence of high blood pressure is higher in migraine patient and contradictory evidence from other research [64-68]. Similarly, the data about the relationship of migraine and obesity are inconsistent. Most studies show that obesity increases the risk of having migraine and the risk grows with increasing BMI $[69,70]$. Total body obesity may impact migraine frequency, severity, and duration [71]. Subsequently, a large body of evidence has highlighted an involvement of obesity in migraine chronification [70-72]. The majority of available studies indicate that there is a positive correlation between cigarette smoking and migraine, revealing that the number of smokers among migraineurs is significantly higher compared with healthy controls [72-74]. Smoking among migraineurs seems to be related to the development of cranial autonomic symptoms, but evidence indicating that tobacco use may trigger headache is lacking $[75,76]$. However, Coronary Artery Risk Development in Young Adults (CARDIA) Study demonstrated an increased risk of developing migraine in young smokers [77]. Studies on the role of dyslipidemia in migraine patients are quite homogenous and demonstrate an association between unfavorable cholesterol profile and migraine, particularly with aura [14]. Fewer studies failed to demonstrate the association between dyslipidemia and migraine or showed negative association $[72,78]$. Based on the available data, we cannot indicate any single risk factor that could play a predominant role in the pathogenesis of stroke in migraineurs.

\section{Patent Foramen Ovale}

Patent foramen ovale (PFO) is linked to cryptogenic stroke and transient ischemic attacks in a mechanism of paradoxical embolism and transient hypoxemia [79-81]. Many, but not all available studies report there is a higher prevalence of PFO in migraineurs, especially with aura [82-86]. Wolff reported $64.7 \%$ of migrainous infarction patients have persistent foramen ovale [28]. As demonstrated by Larossa, PFO is not more common or larger in chronic migraine than in episodic migraine patients [85]. In a subset of migraineurs with stroke, prevalence of PFO was significantly higher and the mean age of stroke was lower than in controls [87]. Numerous observational studies report positive impact of PFO closure on the occurrence of migraine [88-91]. However, the balance between risks and benefits is not favorable enough; therefore, the routine detection and closure of PFO for migraine prevention is not recommended [84, 92, 93].

\section{Underlying Genetic Disorders}

The complexity of the migraine and stroke correlation is seen in genetic vasculopathies such as cerebral autosomal dominant arteriopathy with subcortical infarcts and leukoencephalopathy (CADASIL). Mitochondrial encephalopathy with lactic acidosis and stroke (MELAS), cerebroretinal vasculopathy, and hereditary endotheliopathy with retinopathy, nephropathy and stroke (HERNS) are other genetic disorders connecting migraine and stroke-like episodes; however, these interesting topics remain beyond the scope of this article. Apart from these disorders, other genetic factors seem to play a role in the discussed correlation. Data from a recent, large, genome-wide analysis study indicate that the strongest genetic overlap exists between migraine without aura and large artery stroke, and cardio-embolic stroke [94]. Genetic factors do not seem to play an important role in a shared pathogenesis of stroke and migraine with aura [94].

\section{Cerebral Autosomal Dominant Arteriopathy with Subcortical Infarcts and Leukoencephalopathy}

Cerebral autosomal dominant arteriopathy with subcortical infarcts and leukoencephalopathy (CADASI) is an autosomal dominant disease caused by rare mutations of the gene encoding the neurogenic locus notch homolog protein 3 (NOTCH 3 gene) located on chromosome 19p13 [95]. The gene encodes a vascular smooth muscle cells receptor. Its defect leads to chronic white matter ischemia due to nonartheriosclerotic, non-amyloid vasculopathy with fibrosis and an accumulation of granular and osmiophilic substances perforating cerebral arteries [96, 97]. Stroke risk among these patients is enhanced. It should be suspected when a patient has one or more of recurrent subcortical ischemic strokes at the mean age of 45 years, especially in the absence of other risk factors, migraine (typically with aura) and/or early cognitive decline, or subcortical dementia usually associated with pseudobulbar palsy [34, 98]. Migraine, typically with aura, occurs in about $30 \%$ of patients. It is usually the earliest symptom, and in some patients the only clinical manifestation of the 
disease [98]. In most cases attacks of migraine improve or cease when other manifestations of CADASIL (e.g., ischemic stroke) appear [29]. Magnetic resonance imaging is always abnormal with well delineated, small, bilateral infarcts typically seen in the deep white matter and in the periventricular region predominantly in the frontal, parietal and anterior temporal lobes, rarely in the occipital lobes [99].

Familial hemiplegic migraine (FMH) is a rare (5/100 000), autosomal dominant disease, the subtypes of which are caused by mutation on the CACNA1A, ATP1A2, SCN1A or PRRT2 genes [34, 100, 101]. FHM is characterized by reversible motor weakness, which may resemble stroke or transient ischemic attack [29]. Studies indicate that FHM increases susceptibility to spreading depression and enhances ischemic vulnerability of migraine brain [102].

\section{Migraine Drugs}

Migraine specific drugs, triptans and ergotamines, may induce vasoconstriction that putatively could enhance stroke risk [103]. Several studies on triptan safety reveal conflicting results, so no firm conclusion can be drawn [104, 105]. However, by analyzing the available data we may speculate that even if the absolute risk of stroke is enhanced in patients recently exposed to triptans, the risk is small and estimated at 1:100,000 treated attacks for sumatriptan [106]. Therefore, in light of current knowledge, minding their effectiveness in treating migraine we should always take triptans into consideration as a treatment option. As migraine is a disorder that particularly concerns young woman in the fertile period of life, contraceptive pills are often required [107]. Furthermore, in menstrual related migraine, stabilizing estrogen level by use of contraceptive pills may decrease the intensity and duration of menstrual related migraine attacks [108, 109]. Some headache specialists are still cautious with their use for fear of increasing stroke risk. Most of the past studies evaluating the effect of oral contraceptive pills on the course of migraine and stroke risk were based on high dose estrogen pills 50 to $100 \mathrm{mcg}$ of ethynyl estradiol. Current evidence demonstrates that new, low-dose oral contraceptives $(25 \mathrm{mcg}$ of ethynyl estradiol or less) do not enhance vascular risk in migraine woman [110].

\section{Conclusions}

A large body of evidence supports the link between migraine and ischemic stroke. The subset of patients at the most increased risk of stroke are young females with migraine with aura and patients suffering from genetic disorders like CADASIL, MELAS, and HERNS. A 2-fold increased risk of ischemic stroke in migraine with aura patients has been noted in some population-based studies [22, 29, 111].
Migraineurs, particularly at heightened risk of stroke, should be encouraged to manage other risk factors for stroke, like hypertension, diabetes, obesity, elevated homocysteine, and dyslipidemia, as it seems to be a reasonable approach to decrease the overall risk of stroke. A firm recommendation not to smoke should be made. Evidence suggests that we should not be afraid of using low-estrogen contraceptives in females with migraine, especially when non-hormonal preventive treatment has been unsuccessful $[107,112]$. A firm correlation between the frequency of migraine attacks and the risk of stroke exists; however, there are no data indicating that migraine prophylaxis decreases the risk of migrainous infarct [113]. Keeping in mind the aspect of quality of life in migraineurs, we should always consider use of migrainespecific abortive drugs, remembering that in female migraineurs the absolute risk of stroke is low [114]. Considering that we lack sufficient proof to justify any of the known factors having a predominant role in migraine stroke relation, further investigation is a necessary. It should focus on answering the question whether stroke in migraine with aura patients might be prevented, and by which therapeutic strategies.

\section{Compliance with Ethical Standards}

Conflict of Interest Anna Gryglas and Robert Smigiel declare that they have no conflict of interest.

Human and Animal Rights and Informed Consent This article does not contain any studies with human or animal subjects performed by any of the authors.

Open Access This article is distributed under the terms of the Creative Commons Attribution 4.0 International License (http:// creativecommons.org/licenses/by/4.0/), which permits unrestricted use, distribution, and reproduction in any medium, provided you give appropriate credit to the original author(s) and the source, provide a link to the Creative Commons license, and indicate if changes were made.

\section{References}

Papers of particular interest, published recently, have been highlighted as:

- Of importance

1. Harriott AM, Barrett KM. Dissecting the association between migraine and stroke. Curr Neurol Neurosci Rep. 2015;15:5.

2. Mawet J, Kurth T, Ayata C. Migraine and stroke: in search of shared mechanisms. Cephalalgia. 2015;35:165-81. This extended literature review article reveals recent clinical evidence linking migraine and stroke. In the light of current knowledge, it clarifies the mechanisms of association between migraine and stroke, opportunities for the risk factor screening, management of acute stroke, and stroke prophylaxis.

3. Feigin VL, Forouzanfar MH, Krishnamurthi R, Mensah GA, Connor M, Bennett DA, et al. Global and regional burden of 
stroke during 1990-2010: findings from the Global Burden of Disease Study 2010. Lancet. 2014;383:245-54.

4. Global Health Estimates. Geneva: World Health Organization; 2012. Available at: http://www.who.int/healthinfo/global_ burden disease/en/Accessed October 2, 2016.

5. Go AS, Mozaffarian D, Roger VL, Benjamin EJ, Berry JD, Blaha MJ, et al. Heart disease and stroke statistics-2014 update: a report from the American Heart Association. Circulation. 2014;129:28 292

6. Barker-Collo S, Bennett DA, Krishnamurthi RV, Parmar P, Feigin VL, Naghavi M, et al. Sex differences in stroke incidence, prevalence, mortality and disability-adjusted life years: results from the Global Burden of Disease Study 2013. Neuroepidemiology. 2015;45:203-14

7. Victor TW, Hu X, Campbell JC, Buse DC, Lipton RB. Migraine prevalence by age and sex in the United States: a life-span study. Cephalalgia. 2010;30:1065-72.

8. Burch RC, Loder S, Loder E, Smitherman TA. The prevalence and burden of migraine and severe headache in the United States: updated statistics from government health surveillance studies. Headache. 2015;55:21-34.

9. Krishnamurthi RV, Moran AE, Feigin VL, Barker-Collo S, Norrving B, Mensah GA, et al. Stroke prevalence, mortality and disability-adjusted life years in adults aged 20-64 years in 19902013: data from the Global Burden of Disease 2013 Study. Neuroepidemiology. 2015;45:190-202.

10. Lee MJ, Lee C, Chung CS. The migraine-stroke connection. J Stroke. 2016;18:146-56.

11. Sacco S, Kurth T. Migraine and the risk for stroke and cardiovascular disease. Curr Cardiol Rep. 2014;16:524.

12. Gudmundsson LS, Scher AI, Aspelund T, Eliasson JH, Johannsson M, Thorgeirsson G, et al. Migraine with aura and risk of cardiovascular and all cause mortality in men and women: prospective cohort study. BMJ. 2010;341:3966.

13. Kurth T, Winter AC, Eliassen AH, Dushkes R, Mukamal KJ, Rimm EB, et al. Migraine and risk of cardiovascular disease in women: prospective cohort study. BMJ. 2016;353:2610.

14. Wang YC, Lin CW, Ho YT, Huang YP, Pan SL. Increased risk of ischemic heart disease in young patients with migraine: a population-based, propensity score-matched, longitudinal follow-up study. Int J Cardiol. 2014;172:213-6.

15. O'Keeffe ST, Tsapatsaris NP, Beetham Jr WP. Association between Raynaud's phenomenon and migraine in a random population of hospital employees. J Rheumatol. 1993;20:1187-8.

16. Sacco S, Ornello R, Ripa P, Pistoia F, Carolei A. Migraine and hemorrhagic stroke: a meta-analysis. Stroke. 2013;44:3032-8.

17. Sacco S, Ricci S, Carolei A. Migraine and vascular diseases: a review of the evidence and potential implications for management. Cephalalgia. 2012;32:785-95.

18. Gaist D, González-Pérez A, Ashina M, Rodríguez LA. Migraine and risk of hemorrhagic stroke: a study based on data from general practice. J Headache Pain. 2014;15:74.

19. Malik R, Freilinger T, Bendik S, Winsvold BS, Anttila V, Vander Heiden J, et al. Shared genetic basis for migraine and ischemic stroke. A genome-wide analysis of common variants. Neurology. 2015;84:2132-45.

20. Schurks M, Rist PM, Bigal ME, Buring JE, Lipton RB, Kurth T. Migraine and cardiovascular disease: systematic review and metaanalysis. BMJ. 2009;339:3914.

21. Etminan M, Takkouche B, Isorna FC, Samii A. Risk of ischaemic stroke in people with migraine: systematic review and metaanalysis of observational studies. BMJ. 2005;330:63.

22. Spector JT, Kahn SR, Jones MR, Jayakumar M, Dalal D, Nazarian $\mathrm{S}$. Migraine headache and ischemic stroke risk: an updated metaanalysis. Am J Med. 2010;123:612-24.
23. Kurth T, Chabriat H, Bousser MG. Migraine and stroke: a complex association with clinical implications. Lancet Neurol. 2012;11:92-100.

24. De Falco FA, de Falco A. Migraine with aura: which patients are most at risk of stroke? Neurol Sci. 2015;36:57-60.

25. MacClellan LR, Giles W, Cole J, Wozniak M, Stern B, Mitchell BD, et al. Probable migraine study. Stroke. 2007;38:2438-45.

26. Norton J, Portet F, Gabelle A, Debette S, Ritchie K, Touchon J, et al. Are migraine and non-migrainous headache risk factors for stroke in the elderly? Findings from a 12-year cohort follow-up. Eur J Neurol. 2016;23:1463-70.

27. Kruit MC, van Buchem MA, Launer LJ, Terwindt GM, Ferrari MD. Migraine is associated with an increased risk of deep white matter lesions, subclinical posterior circulation infarcts and brain iron accumulation. The population-based MRI CAMERA-study. Cephalalgia. 2010;30:129-36.

28. Wolf ME, Szabo K, Griebe M, Förster A, Gass A, Hennerici MG, et al. Clinical and MRI characteristics of acute migrainous infarction. Neurology. 2011;76:1911-7.

29. Olesen J. Headache classification committee of the international headache society (IHS). The international classification of headache disorders, 3rd edition (beta version). Cephalalgia. 2013;33: 629-808.

30. Laurell K, Artto V, Bendtsen L, Hagen K, Kallela M, Meyer EL, et al. Migrainous infarction: a Nordic multicenter study. Eur J Neurol. 2011;18:1220-6.

31. Scher AI, Gudmundsson LS, Sigurdsson S, Ghambaryan A, Aspelund T, Eiriksdottir G. Migraine headache in middle age and late-life brain infarcts. JAMA. 2009;301:2563-70.

32. Vincent $M$, Hadjikhani N. The cerebellum and migraine. Headache. 2007;47:820-33.

33. Porter A, Gladstone JP, Dodick DW. Migraine and white matter hyperintensities. Curr Pain Headache Rep. 2005;9:289-93.

34. Gladstone JP, Dodick DW. Migraine and cerebral white matter lesions: when to suspect cerebral autosomal dominant arteriopathy with subcortical infarcts and leukoencephalopathy (CADASIL). Neurologist. 2005;11:19-29.

35. Bashir A, Lipton RB, Ashina S, Ashina M. Migraine and structural changes in the brain: a systematic review and meta-analysis. Neurology. 2013;81:1260-8.

36. Rist PM, Dufouil C, Glymour MM, Tzourio C, Kurth T. Migraine and cognitive decline in the population-based EVA study. Cephalalgia. 2011;31:1291-300.

37. Eikermann-Haerter K. Spreading depolarization may link migraine and stroke. Headache. 2014;54:1146-57.

38. Stam AH, Haan J, van den Maagdenberg AM, Ferrari MD, Terwindt GM. Migraine and genetic and acquired vasculopathies. Cephalalgia. 2009;29:1006-17.

39. Bigal ME, Kurth T, Santanello N, Buse D, Golden W, Robbins M, et al. Migraine and cardiovascular disease: a population-based study. Neurology. 2010;74:628-35.

40. Schürks M, Buring JE, Ridker PM, Chasman DI, Kurth T. Genetic determinants of cardiovascular events among women with migraine: a genome-wide association study. PLoS One. 2011;6: 22106.

41. Artto V, Metso TM, Metso AJ, Putaala J, Haapaniemi E, Wessman $\mathrm{M}$, et al. Migraine with aura is a risk factor for cervical artery dissection: a case-control study. Cerebrovasc Dis. 2010;30:36-40.

42. Longoni M, Ferrarese C. Inflammation and excitotoxicity: role in migraine pathogenesis. Neurol Sci. 2006;27:107-10.

43. Tietjen GE. Migraine as a systemic disorder. Neurology. 2007;68: 1555-6.

44. Eikermann-Haerter K, Ayata C. Cortical spreading depression and migraine. Curr Neurol Neurosci Rep. 2010;10:167-73. 
45. Ayata C, Lauritzen M. Spreading depression, spreading depolarizations, and the cerebral vasculature. Physiol Rev. 2015;95:95393.

46. Lauritzen M, Strong AJ. Spreading depression of Leão' and its emerging relevance to acute brain injury in humans. J Cereb Blood Flow Metab. 2016.

47. Kazemi H, Speckmann EJ, Gorji A. Familial hemiplegic migraine and spreading depression. Iran J Child Neurol. 2014;8:6-11.

48. Tietjen EG. Migraine and ischaemic heart disease and stroke: potential mechanisms and treatment implications. Cephalalgia. 2007;27:981-7.

49. Gursoy-Ozdemir Y, Qiu J, Matsuoka N, Bolay H, Bermpohl D, Jin $\mathrm{H}$, et al. Cortical spreading depression activates and upregulates MMP-9. J Clin Invest. 2004;113:1447-55.

50. Piilgaard H, Lauritzen M. Persistent increase in oxygen consumption and impaired neurovascular coupling after spreading depression in rat neocortex. J Cereb Blood Flow Metab. 2009;29:151727.

51. Somjen GG. Mechanisms of spreading depression and hypoxic spreading depression- like depolarisation. Physiol Rev. 2001;81: $1065-9$.

52. Seitz I, Dirnagl U, Lindauer U. Impaired vascular reactivity of isolated rat middle cerebral artery after cortical spreading depression in vivo. J Cereb Blood Flow Metab. 2004;24:526-30.

53. Bigal ME. Migraine and cardiovascular disease. Arq Neuropsiquiatr. 2011;69:122-9.

54. Dreier JP. The role of spreading depression, spreading depolarization and spreading ischemia in neurological disease. Nat Med. 2011;17:439-47.

55. Tietjen GE. Circulating microparticles in migraine with aura: cause or consequence, a link to stroke. Cephalalgia. 2015;35:857.

56. Rajendran P, Rengarajan T, Thangavel J, Nishigaki Y, Sakthisekaran D, Sethi G, et al. The vascular endothelium and human diseases. Int J Biol Sci. 2013;9:1057-69.

57. Liman TG, Bachelier-Walenta K, Neeb L, Rosinski J, Reuter U, Böhm M, et al. Circulating endothelial microparticles in female migraineurs with aura. Cephalalgia. 2015;35:88-94.

58. Tietjen GE, Herial NA, White L, Utley C, Kosmyna JM, Khuder SA. Migraine and biomarkers of endothelial activation in young women. Stroke. 2009;40:2977-82.

59. Rodríguez-Osorio X, Sobrino T, Brea D, Martínez F, Castillo J, Leira R. Endothelial progenitor cells: a new key for endothelial dysfunction in migraine. Neurology. 2012;79:474-9.

60. Vernieri F, Tibuzzi F, Pasqualetti P, Altamura C, Palazzo P, Rossini $\mathrm{PM}$, et al. Increased cerebral vasomotor reactivity in migraine with aura: an autoregulation disorder? A transcranial Doppler and nearinfrared spectroscopy study. Cephalalgia. 2008;28:689-95.

61. Akin A, Bilensoy D. Cerebrovascular reactivity to hypercapnia in migraine patients measured with near- infrared spectroscopy. Brain Res. 2006;1107:206-14.

62. Rajan R, Khurana D, Lal V. Interictal cerebral and systemic endothelial dysfunction in patients with migraine: a case-control study. J Neurol Neurosurg Psychiatry. 2015;86:1253-7.

63. Scher AI, Terwindt GM, Picavet HS, Verschuren WM, Ferrari MD, Launer LJ. Cardiovascular risk factors and migraine: the GEM population-based study. Neurology. 2005;64:614-20.

64. Pires PW, Dams Ramos CM, Matin N, Dorrance AM. The effects of hypertension on the cerebral circulation. Am J Physiol Heart Circ Physiol. 2013;304:1598-614.

65. Ikeda K, Kawase Y, Takazawa T, Kano O, Tamura M, Iwasaki Y. Cardiovascular disease risk profile in Japanese midlife migraineurs. J Neurol Res. 2012;2:10-5.

66. Gardener H, Monteith T, Rundek T, Wright CB, Elkind MS, Sacco RL. Hypertension and Migraine in the Northern Manhattan Study. Ethn Dis. 2016;26:323-30.
67. Tronvik E, Zwart JA, Hagen K, et al. Association between blood pressure measures and recurrent headache in adolescents: crosssectional data from the HUNT Youth study. J Headache Pain. 2011;12:347-53.

68. Hagen K, Stovner LJ, Vatten L, Holmen J, Zwart JA, Bovim G. Blood pressure and risk of headache: a prospective study of 22 , 685 adults in Norway. J Neurol Neurosurg Psychiatry. 2002;72: 463-6.

69. Queiroz LP, Peres MF, Piovesan EJ, Kowacs F, Ciciarelli MC, Souza JA, et al. A nationwide population-based study of migraine in Brazil. Cephalalgia. 2009;29:642-9.

70. Ornello R, Ripa P, Pistoia F, Degan D, Tiseo C, Carolei A, et al. Migraine and body mass index categories: a systematic review and meta-analysis of observational studies. J Headache Pain. 2015;16: 27.

71. Ligong Z, Jinjin Q, Chunfu C, Congcong L, Xiaojun D. Effect of obesity and leptin level on migraineurs. Med Sci Monit. 2015;21: 3270-4.

72. Winsvold BS, Hagen K, Aamodt AH, Stovner LJ, Holmen J, Zwart JA. Headache, migraine and cardiovascular risk factors: The HUNT study. Eur J Neurol. 2011;18:504-11.

73. Le H, Tfelt-Hansen P, Skytthe A, Kyvik KO, Olesen J. Association between migraine, lifestyle and socioeconomic factors: a population-based cross-sectional study. J Headache Pain. 2011;12:157-72.

74. Sacco S, Pistoia F, Degan D, Carolei A. Conventional vascular risk factors: their role in the association between migraine and cardiovascular diseases. Cephalalgia. 2015;35:146-64.

75. Rozen TD. A history of cigarette smoking is associated with the development of cranial autonomic symptoms with migraine headaches. Headache. 2011;51:85-91.

76. Taylor FR. Tobacco, nicotine, and headache. Headache. 2015;55: 1028-44.

77. Hozawa A, Houston T, Steffes MW, Widome R, Williams OD, Iribarren $\mathrm{C}$, et al. The association of cigarette smoking with selfreported disease before middle age: the Coronary Artery Risk Development in Young Adults (CARDIA) study. Prev Med. 2006;42:193-9.

78. Rockett FC, Perla Ada S, Perry ID, Chaves ML. Cardiovascular disease risk in women with migraine. J Headache Pain. 2013;14: 75.

79. Katsarava Z, Weimar C. Migraine and stroke. J Neurol Sci. 2010;299:42-4.

80. Zier LS, Sievert H, Mahadevan VS. To close or not to close: contemporary indications for patent foramen ovale closure. Expert Rev Cardiovasc Ther. 2016;10:1-10.

81. Taramasso M, Nietlispach F, Maisano F, Meier B. Patent foramen ovale: indications for closure and techniques. EuroIntervention. 2016;12:7-12.

82. Kahya Eren N, Bülbül NG, Yakar Tülüce S, Nazlı C, Beckmann Y. To be or not to be patent: the relationship between migraine and patent foramen ovale. Headache. 2015;55:934-42.

83. Schwedt TJ, Demaerschalk BM, Dodick DW. Patent foramen ovale and migraine: a quantitative systematic review. Cephalalgia. 2008;28:531-40.

84. Ailani J. Migraine and patent foramen ovale. Curr Neurol Neurosci Rep. 2014;14:426.

85. Larrosa D, Ramón C, Alvarez R, Martínez-Camblor P, Cernuda E, Pascual J. No relationship between patent foramen ovale and migraine frequency. Headache. 2016;56:1466-73.

86. Dowson A, Mullen MJ, Peatfield R, Muir K, Khan AA, Wells C, et al. Migraine Intervention With STARFlex Technology (MIST) trial: a prospective, multicenter, double-blind, sham-controlled trial to evaluate the effectiveness of patent foramen ovale closure with STARFlex septal repair implant to resolve refractory migraine headache. Circulation. 2008;117:1397-404. 
87. Lantz M, Kostulas K, Waldenlind E, Sjöstrand C. Prevalence of migraine headache in an in-patient stroke population. Acta Neurol Scand. 2015;131:290-7.

88. Butera G, Biondi-Zoccai GG, Carminati M, Caputi L, Usai S, Bussone G, et al. Systematic review and meta-analysis of currently available clinical evidence on migraine and patent foramen ovale percutaneous closure: much ado about nothing? Catheter Cardiovasc Interv. 2010;75:494-504.

89. Papa M, Gaspardone A, Fragasso G, Ajello S, Gioffrè G, Iamele $\mathrm{M}$, et al. Usefulness of transcatheter patent foramen ovale closure in migraineurs with moderate to large right-to-left shunt and instrumental evidence of cerebrovascular damage. Am J Cardiol. 2009; 104:434-9.

90. Chessa M, Colombo C, Butera G, Negura D, Piazza L, Varotto L, et al. Is it too early to recommend patent foramen ovale closure for all patients who suffer from migraine? A single-centre study. J Cardiovasc Med. 2009;10:401-5.

91. Wahl A, Praz F, Tai T, Findling O, Walpoth N, Nedeltchev K, et al. Improvement of migraine headaches after percutaneous closure of patent foramen ovale for secondary prevention of paradoxical embolism. Heart. 2010;96:967-73. doi:10.1136/hrt.2009.181156.

92. Finocchi C, Del Sette M. Migraine with aura and patent foramen ovale: myth or reality? Neurol Sci. 2015;36:61-6.

93. Tobis J, Charles A, Silberstein SD, Sorensen S, Maini B, Horwitz PA, et al. TCT-30 PREMIUM Trial: Double blind study of percutaneous closure of patent foramen ovale with the AMPLATZER $®$ PFO Occluder as a treatment for migraine with or without aura. J Am Coll Cardiol 2015;66.

94. Malik R, Freilinger T, Winsvold BS, Anttila V, Vander Heiden J, Traylor M, et al. Shared genetic basis for migraine and ischemic stroke: a genome-wide analysis of common variants. Neurology. 2015;84:2132-45.

95. Zhu S, Nahas SJ. CADASIL: imaging characteristics and clinical correlation. Curr Pain Headache Rep. 2016;20:57.

96. Moreton FC, Razvi SS, Davidson R, Muir KW. Changing clinical patterns and increasing prevalence in CADASIL. Acta Neurol Scand. 2014;130:197-203.

97. Yamamoto Y, Craggs LJ, Watanabe A, Booth T, Attems J, Low $\mathrm{RW}$, et al. Brain microvascular accumulation and distribution of the NOTCH3 ectodomain and granular osmiophilic material in CADASIL. J Neuropathol Exp Neurol. 2013;72:416-31.

98. Silberstein SD, Lipton RB, Dalessio DJ. Wolff's Headache and other head pain. In: Silberstein SD, Saper JR, Freitag FG, editors. Migraine: diagnosis and treatment. Oxford: Oxford University Press; 2001.

99. Stojanov D, Vojinovic S, Aracki-Trenkic A, Tasic A, BenedetoStojanov D, Ljubisavljevic S, et al. Imaging characteristics of cerebral autosomal dominant arteriopathy with subcortical infarcts and leucoencephalopathy (CADASIL). Bosn J Basic Med Sci. 2015; 15:1-8.

100. Fan C, Wolking S, Lehmann-Horn F, Hedrich UB, Freilinger T, Lerche H. Early-onset familial hemiplegic migraine due to a novel SCN1A mutation. Cephalalgia. 2016.

101. Weng TH, Chiu WT, Afilalo M, Choy CS, Tselios C, Yip PK. A young man presenting with acute encephalopathy, hemiparesis, and headache. J Emerg Med. 2012;43:258-62.

102. Eikermann-Haerter K, Lee JH, Yuzawa I, Liu CH, Zhou Z, Shin HK. Migraine mutations increase stroke vulnerability by facilitating ischemic depolarizations. Circulation. 2012;125:335-45.

103. Roberto G, Raschi E, Piccinni C, Conti V, Vignatelli L, D'Alessandro R. Adverse cardiovascular events associated with triptans and ergotamines for treatment of migraine: systematic review of observational studies. Cephalalgia. 2015;35:118-31.

104. Becker C, Brobert GP, Almqvist PM, Johansson S, Jick SS, Meier $\mathrm{CR}$. Migraine and the risk of stroke, TIA, or death in the UK (CME). Headache. 2007;47:1374-84.

105. Velentgas P, Cole JA, Mo J, Sikes CR, Walker AM. Severe vascular events in migraine patients. Headache. 2004;44:642-51.

106. Martin VT, Goldstein JA. Evaluating the safety and tolerability profile of acute treatments for migraine. Am J Med. 2005;118: 36- 44.

107. Faubion SS, Casey PM, Shuster LT. Hormonal contraception and migraine: clinical considerations. Curr Pain Headache Rep. 2012;16:461-6.

108. Calhoun AH. Hormonal contraceptives and migraine with auraIs there still a risk? Headache. 2016.

109. Calhoun A. Combined hormonal contraceptives: is it time to reassess their role in migraine? Headache. 2012;52:648-60.

110. Martin VT, Behbehani M. Ovarian hormones and migraine headache: understanding mechanisms and pathogenesis-part 2. Headache. 2006;46:365-86.

111. Schürks M, Rist PM, Bigal ME, Buring JE, Lipton RB, Kurth T. Migraine and cardiovascular disease: systematic review and metaanalysis. BMJ. 2009;339:3914.

112. Calhoun A, Ford S, Pruitt A. The impact of extended-cycle vaginal ring contraception on migraine aura: a retrospective case series. Headache. 2012;52:1246-53.

113. Silberstein SD, Lipton RB, Dalessio DJ. Wolff's Headache and other head pain. In: Bousser MG, Good J, Kittner SJ, Silberstein SD, editors. Headache associated with vascular disorders. Oxford: Oxford University Press; 2001.

114. Kurth T, Gaziano JM, Cook NR, Logroscino G, Diener HC, Buring JE. Migraine and risk of cardiovascular disease in women. JAMA. 2006;296:283-91. 